\title{
Food Allergy and Anaphylaxis in Infants and Preschool-Age Children
}

\author{
João Gaspar-Marques, MD ${ }^{1,2}$, Pedro Carreiro-Martins, MD, $P^{1,2}$, \\ Ana Luísa Papoila, $\mathbf{P h D}^{3}$, lolanda Caires, $\mathrm{MSc}^{2}$, Catarina Pedro, $\mathbf{M S c}^{2}$, \\ José Araújo-Martins, MD, MSc ${ }^{2}$, Daniel Virella, MD, MSc', José Rosado-Pinto, \\ $M^{4}$, Paula Leiria-Pinto, MD, MSc ${ }^{1,2}$, and Nuno Neuparth, MD, PhD ${ }^{1,2}$
}

\begin{abstract}
Food allergy (FA) prevalence data in infants and preschool-age children are sparse, and proposed risk factors lack confirmation. In this study, 19 children's day care centers (DCC) from 2 main Portuguese cities were selected after stratification and cluster analysis. An ISAAC's (International Study of Asthma and Allergies in Childhood) derived health questionnaire was applied to a sample of children attending DCCs. Outcomes were FA parental report and anaphylaxis. Logistic regression was used to explore potential risk factors for reported FA. From the 2228 distributed questionnaires, 1217 were included in the analysis (54.6\%). Children's median age was 3.5 years, and $10.8 \%$ were described as ever having had FA. Current FA was reported in $5.7 \%$. Three $(0.2 \%)$ reports compatible with anaphylaxis were identified. Reported parental history of FA, personal history of atopic dermatitis, and preterm birth increased the odds for reported current FA. A high prevalence of parental-perceived FA in preschool-age children was identified. Risk factor identification may enhance better prevention.
\end{abstract}

\section{Keywords}

anaphylactic reaction, children, food allergy, prevalence, risk factors

\section{Introduction}

The concept of food allergy (FA) is related to an immune response directed toward food. ${ }^{1}$ This definition encompasses immune responses that are IgE mediated, nonIgE mediated, or a combination of both, and it has been adopted by several international guidelines. ${ }^{2-4}$ Food allergies can result in life-threatening reactions and diminish quality of life. ${ }^{5}$ In the past several decades, the prevalence of FA has increased in several regions throughout the world. Although more than 170 foods have been identified as being potentially allergenic, a minority of these foods cause the majority of reactions, and common food allergens vary between geographic regions. ${ }^{5}$

Food-induced anaphylaxis is a serious allergic reaction, with rapid onset that can cause death ${ }^{6}$ and is the most common cause of anaphylaxis in children. ${ }^{7-9}$ IgEmediated food-induced anaphylaxis involves systemic mediator release from sensitized mast cells and basophils. Published clinical criteria guidelines for defining anaphylaxis in children include an acute onset of illness and a combination of 2 or more clinical findings: mucocutaneous involvement, respiratory/cardiovascular compromise, and persistent gastrointestinal symptoms. ${ }^{10}$
Determining the prevalence of FA is challenging and the double-blind, placebo-controlled food challenge is the most reliable indicator of FA. ${ }^{5}$ However, using this challenge in prevalence studies is difficult because the format is time-consuming and not all foods are easily masked. ${ }^{5}$ On the other hand, epidemiological data on parental-perceived food reactions are needed for predicting utilization of health care services. ${ }^{11}$

As for FA in general, the risk of food-induced anaphylaxis in childhood also cannot be accurately assessed because there are minimal pediatric data and there are major methodological differences between available studies. ${ }^{10}$ For example, some reports claim that the incidence of anaphylaxis is superior in children than in

\footnotetext{
'Hospital de Dona Estefânia, Lisbon, Portugal

${ }^{2}$ CEDOC, Faculdade de Ciências Médicas, Universidade Nova de Lisboa, I I 69-056 Lisbon, Portugal

${ }^{3}$ Departamento de Bioestatística e Informática, CEAUL,

Universidade Nova de Lisboa, I $169-056$ Lisbon, Portugal

${ }^{4}$ Hospital da Luz, I500-650 Lisbon, Portugal

Corresponding Author:

João Gaspar-Marques, Hospital de Dona Estefânia, Rua Jacinta

Marto, I 169-045 Lisbon, Portugal.

Email: gasparmarques@yahoo.com.br
} 
adults, ${ }^{12}$ whereas others report that it is inferior. ${ }^{13}$ Different approaches have been used to explore the epidemiology of anaphylaxis. As an example, in a survey of all French school children, it was estimated that 1 in 1000 have personalized anaphylaxis management plans. $^{14}$

Data about the prevalence of self-reported FA morbidity have been published, but the results are sparse and dissimilar. ${ }^{11,15-17}$ A US cross-sectional survey with 40 104 included children described a childhood prevalence of FA of 8.0\% ${ }^{17}$ In a British cohort of 757 11-year-old children, a point prevalence of $11.6 \%$ in children aged 11 years and $12.4 \%$ in those aged 15 years was found. ${ }^{15}$ A French questionnaire-based survey estimated a current prevalence of $6.8 \%$ in children aged 6 to 11 years and $3.4 \%$ in those aged 11 to 14 years. ${ }^{16}$ The lifetime prevalence of perceived FA has been reported to vary from $2.4 \%$ to $12.4 \%{ }^{16}$

Few studies are available in preschool-age children. Data from the previously cited US cross-sectional survey ${ }^{17}$ identified a parental FA perception prevalence rate of $6.3 \%$ among the evaluated 5429 children, 0 to 2 years of age, and $9.2 \%$ in 5910 children, 3 to 5 years old. A Finnish study reports a combined lifetime prevalence of FA perceived by parents only and FA diagnosed by a physician of $30 \%$ among 1 - to 4 -year-old children. ${ }^{18}$ A UK study reported a cumulative incidence of $26 \%$ for parental-perceived FA by 1 year of age and 34\% for 3-year-old children, whereas the incidences of FA confirmed by controlled food challenges and "a clear convincing clinical history" were $3 \%$ and $5 \%$, respectively. ${ }^{19}$

Added to the impact of pediatric FA on public health, the number of children with FA seems to be increasing. ${ }^{20}$ Assuming the FA prevalence increase, FA prevention through allergen avoidance during pregnancy, breastfeeding, and infancy has been seen as an effective public health policy to prevent allergies, although there is not much epidemiological data to support this. ${ }^{21}$

Population-based epidemiological studies have generated numerous novel theories regarding risks, including modifiable factors such as components of the maternal and infant diet, obesity, and the timing of food introduction. ${ }^{22}$ These theories also lack confirmation through other epidemiological studies.

The aims of the current study were to estimate the reported prevalence of FA in preschool-age children and to identify potential risk factors for FA.

\section{Patients and Methods}

\section{Study Population and Design}

This cross-sectional study was conducted in Portugal in the frame of the ENVIRH Project (Environment and Health in Children Day Care Centres). The ENVIRH
Project aimed to evaluate the association between indoor air quality and children's health in day care centers (DCCs). In phase I of the project, 45 DCCs from Lisbon and Oporto were randomly selected after stratification by the parish. In phase II, 19 DCCs were sampled after a cluster analysis based on indoor air quality. At both phases, convenience samples of children attending the selected DCCs were recruited. This article presents data related to phase II only.

ENVIRH study was approved by the Ethics Commission of Faculdade de Ciências Médicas, Universidade Nova de Lisboa. The database was registered and approved by the Portuguese Data Protection Authority (CNPD). Parents were informed about the ENVIRH study and gave signed consent.

\section{FA and Anaphylaxis Assessment}

In the frame of the ENVIRH Project, a children's health questionnaire, derived from the ISAAC's (International Study of Asthma and Allergies in Childhood) questionnaire, was handed out to all children who attended the selected DCCs and was completed by the parents $(\mathrm{n}=$ 2228). This questionnaire included additional information regarding FA to assess its reported prevalence and potential risk factors. The clinical outcome measures were reporting either ever having had a FA reaction, having current FA, or having had anaphylaxis. Anaphylaxis was defined according to the EAACI position paper about management of anaphylaxis in childhood: acute onset after food exposure ( $<30$ minutes), skin and/or mucocutaneous involvement, and at least 1 manifestation of respiratory compromise or cardiovascular dysfunction. Individuals could have any one of the above-listed symptoms along with persistent gastrointestinal symptoms (vomiting).

Two simple questions covered whether the child had ever had an allergic reaction to foods ("Have you ever had a food allergy reaction?") and if he or she was still allergic at the moment the questionnaire was provided ("Is your son still allergic to that food?"). If this was the case, the type of offending food could be reported in a multiple option question (options were milk, egg, fish, chocolate, orange, soy, wheat, peanut, strawberry, peach, nuts, shellfish, and kiwi and a free field for others). Questions for characterization of the FA clinical reaction to the first offending food were also asked: age of first reaction, chronology of the reaction, clinical symptoms, number of reactions, and if the child already tolerates the food.

\section{Statistical Analysis}

The prevalence of clinical outcomes was estimated in the sample as the point prevalence with its $95 \%$ 
Table I. Sociodemographic Characteristics of the Children $(n=1217)$.

\begin{tabular}{lc}
\hline Gender (\%) & \\
$\quad$ Boys & 52.3 \\
$\quad$ Girls & 47.7 \\
Age in years (mean $\pm \mathrm{SD})$ & $3.5 \pm 1.5$ \\
Parental education $(\%)$ & \\
$\quad$ Primary or secondary & 63.7 \\
$\quad$ High school or university & 36.3 \\
Cesarean birth delivery, percentage $(95 \% \mathrm{Cl})$ & $43.1(40.3-45.9)$ \\
Birth weight <2.5 kg, percentage $(95 \% \mathrm{Cl})$ & $13.0(11.2-15.0)$ \\
Preterm birth $(<37$ weeks), percentage $(95 \% \mathrm{Cl})$ & $8.4(7.0-10.1)$ \\
Breastfeeding history, percentage $(95 \% \mathrm{Cl})$ & $91.3(89.5-92.7)$ \\
Atopic dermatitis, percentage $(95 \% \mathrm{Cl})$ & $15.1(13.1-17.3)$ \\
Parental history of food allergy, percentage $(95 \% \mathrm{Cl})$ & $10.5(8.9-12.4)$ \\
\hline
\end{tabular}

Abbreviations: SD, standard deviation; $\mathrm{Cl}$, confidence interval.

confidence intervals (95\% CIs). An exploratory analysis of other variables of interest (gender, age, atopic dermatitis, birth weight $<2.5 \mathrm{~kg}$, gestational age at birth $<37$ weeks, cesarean birth delivery, breast-feeding history, parental education, and parental history of FA) was carried out. Logistic regression models were used to explore potential risk factors for current FA. Crude regression coefficients and corresponding odds ratios (ORs) were first calculated. Adjusted ORs were obtained by multivariable logistic regression models. Variables associated with the clinical outcome measures $(P<.25)$ in the univariable analyses were included in the models. Crude and adjusted ORs were calculated with 95\% CIs. A level of significance of $\alpha=.05$ was considered. Statistical analysis was performed using SPSS (Statistical Package for the Social Sciences; SPSS Inc, Chicago, IL) version 20.0, for Windows.

\section{Results}

From the 2228 distributed questionnaires, 1225 (55.0\%) were returned and 1217 (54.6\%) included in the analysis. The overall mean age was 3.5 (standard deviation = $1.5)$ years; $466(38.3 \%)$ were 0 to 3 years old and 751 $(61.7 \%)$ were 4 to 6 years old. There were $637(52.3 \%)$ boys in the sample. No statistical differences either for gender or age were found between responders and nonresponders. Table 1 summarizes children's sociodemographic characteristics.

\section{Reported FA Prevalence}

In total, 131 children $(10.8 \% ; 95 \% \mathrm{CI}=9.1 \%-12.6 \%)$ were reported as ever having had a FA reaction and 70 $(5.7 \%$; 95\% CI $=4.6 \%-7.2 \%)$ as having current FA. In Table 2, we summarize reported FA prevalence by age group.
Table 2. Reported Prevalence of Food Allergy According to Age Groups ( $n=1217$; Prevalence and 95\% Cl).

\begin{tabular}{lc}
\hline Ever having had a food allergy, percentage $(95 \% \mathrm{Cl})$ & \\
$0-3$ years $(n=466)$ & $8.6(6.4-1 \mid .5)$ \\
$4-6$ years $(n=75 I)$ & $12.1(10.0-14.7)$ \\
Total $(n=1217)$ & $10.8(9.1-12.6)$ \\
Current food allergy, percentage $(95 \% \mathrm{Cl})$ & \\
0-3 years $(n=466)$ & $4.7(3.1-7.0)$ \\
$4-6$ years $(n=75 I)$ & $6.4(4.9-8.4)$ \\
Total $(n=1217)$ & $5.7(4.6-7.2)$ \\
\hline
\end{tabular}

Abbreviation: $\mathrm{Cl}$, confidence interval.

Table 3. Frequencies of the Reported Foods $(n=1217)$.

\begin{tabular}{lccc}
\hline & \multicolumn{3}{c}{ Age Groups (years) } \\
\cline { 2 - 4 } Food & $0-3(\mathrm{n}=466)$, & $4-6(\mathrm{n}=75 \mathrm{I})$, & Total $(\mathrm{n}=12$ I I $)$, \\
& $\mathrm{n}(\%)$ & $\mathrm{n}(\%)$ & $34(2.8)$ \\
\hline Milk & $7(1.5)$ & $27(3.6)$ & $28(2.3)$ \\
Strawberry & $9(1.9)$ & $19(2.5)$ & $17(1.4)$ \\
Chocolate & $4(0.9)$ & $13(1.7)$ & $12(1.0)$ \\
Egg & $5(1.0)$ & $7(0.9)$ & $9(0.7)$ \\
Shellfish & $4(0.9)$ & $5(0.7)$ & $7(0.6)$ \\
Kiwi & $3(0.6)$ & $4(0.5)$ & $6(0.5)$ \\
Orange & $4(0.9)$ & $2(0.3)$ & $6(0.5)$ \\
Peanut & - & $6(0.8)$ & $4(0.3)$ \\
Nuts & - & $4(0.5)$ & $3(0.2)$ \\
Fish & $3(0.6)$ & - & $3(0.2)$ \\
Peach & $1(0.2)$ & $2(0.3)$ & $2(0.2)$ \\
Wheat & $1(0.2)$ & $1(0.1)$ & - \\
Soy & - & - & $37(3.0)$ \\
Others & $14(3.0)$ & $23(3.0)$ & \\
\hline
\end{tabular}

Globally, the most commonly reported offending foods were milk $(2.8 \%)$, strawberry $(2.3 \%)$, chocolate (1.4\%), egg (1.0\%), and shellfish (0.7\%). In 37 cases, the reported food was not prespecified in the questionnaire. Table 3 presents the reported prevalence of each food by age group.

The clinical pattern of the reactions to the first eliciting food was also evaluated. The median age at the first reaction was 12 months $\left(\mathrm{P}_{25}-\mathrm{P}_{75}: 6-24\right.$ months $)$. The reaction was reported as having had acute onset (0-2 hours after exposure) in $55 \%$ of the cases $(28.4 \%$ in the first 30 minutes); late reactions (more than 2 hours) were reported in $45 \%$ of the cases. Mucocutaneous involvement was reported in $70 \%$ of the events, gastrointestinal in $30 \%$, and respiratory symptoms in $4 \%$. Detailed evaluation of mucocutaneous manifestations revealed that $59 \%$ of the patients had rash, $21 \%$ pruritus, and $12 \%$ angioedema. Gastrointestinal manifestations were diarrhea in $22 \%$ of the patients, vomiting in $14 \%$ and abdominal pain in $12 \%$.

Three $(0.2 \%)$ children with reports compatible with anaphylaxis were identified (95\% CI $=0.09 \%-0.7 \%$ ). 
Reported eliciting foods were milk in one case, fish in another, and kiwi in the third.

\section{Factors Associated With FA}

The factors that were significantly associated with reported current FA in the univariable analysis were parental history of FA, personal history of atopic dermatitis, and preterm birth ( $<37$ weeks of gestational age). In the multivariable analysis, all these variables remained significant in the final model, adjusted to age. Other analyzed factors considered nonsignificant were age, gender, parental education, breastfeeding, Cesarean delivery, parental smoking, and birth weight. Table 4 describes the studied potential risk factors for FA and the corresponding ORs.

Table 4. Relationships Between Several Children and Parent's Characteristics and Current Food Allergy. ${ }^{a}$

\begin{tabular}{|c|c|c|}
\hline & Crude Odds Ratios ( $95 \% \mathrm{Cl}$ ) & Adjusted Odds Ratios $(95 \% \mathrm{Cl})$ \\
\hline Gender & $0.865(0.53-I .4 I), P=.558$ & $-^{b}$ \\
\hline Age (years) & $1.09(0.94-I .26), P=.244$ & $1.12(0.95-1.32), P=.186$ \\
\hline Atopic dermatitis & $2.52(1.46-4.37), P=.001$ & 2.10 (1.18-3.73), $P=.012$ \\
\hline Parental history of food allergy & 3.83 (2.19-6.69), $P<.001$ & $3.63(2.02-6.5 \mathrm{I}), P<.00 \mathrm{I}$ \\
\hline Breast-feeding & $1.05(0.44-2.48), P=.918$ & $-^{b}$ \\
\hline Caesarian delivery & $1.26(0.77-2.04), P=.357$ & $-^{b}$ \\
\hline Birth weight $<2.5 \mathrm{~kg}$ & $1.26(0.65-2.46), P=.498$ & $-^{b}$ \\
\hline Preterm birth (<37 weeks) & $1.98(0.98-4.02), P=.059$ & $2.54(\mathrm{I} .2 \mathrm{I}-5.30), P=.013$ \\
\hline Parental education & $0.87(0.52-1.45), P=.593$ & $-^{b}$ \\
\hline
\end{tabular}

Abbreviation: $\mathrm{Cl}$, confidence interval.

${ }^{a}$ The following variables were included in the final model: age, atopic dermatitis, parental history of food allergy, and gestational age at birth $<37$ weeks.

${ }^{\text {b } C o r r e s p o n d i n g ~ f a c t o r ~ n o t ~ s e l e c t e d ~ f o r ~ t h e ~ m u l t i v a r i a b l e ~ a n a l y s i s ~(u n i v a r i a b l e ~} P$ value $>0.25$ ).

\section{Discussion}

The current study estimated a lifetime prevalence of parental perceived allergic reactions to food of $10.8 \%$ and a current prevalence of $5.7 \%$. Data on FA surveys in infants and preschool-age children are scarce, ${ }^{23,24}$ in contrast to that for other allergic diseases. Compared with the previously mentioned published studies from children of the same age group, ${ }^{18,19}$ a considerably lower value of parental perceived FA was found. A possible explanation for this could be geographical differences in reporting FA. McBride et $\mathrm{al}^{25}$ describing the baseline characteristics of the EuroPrevall cohort, reported that self-report of FA among mothers of children enrolled from Germany (30\%), Iceland, the United Kingdom, and the Netherlands (all 20\%-22\%) was considerably more common when compared with those from Italy $(11 \%)$, Lithuania, Greece, Poland, and Spain (all $5 \%-8 \%$ ). The differences in siblings were not as pronounced as in parents but had a similar pattern. ${ }^{25}$ Another possible explanation is a real difference in FA prevalence between countries. In adults, differences in FA prevalence confirmed by oral food challenge have been observed. ${ }^{26}$ Previously, it was speculated that genetic, cultural, and dietary habits could be possible reasons. ${ }^{11}$

The estimates in the current sample were similar to those described in other southern European coun tries. ${ }^{11,25}$ The rising prevalence from the 0 - to 3 -year-old group to the 4- to 6-year-old group has been previously described. ${ }^{17}$ The prevalence of childhood FA in Portugal had been previously estimated at $8.5 \% .{ }^{27}$ However, this study included children $<18$ years old referred to an allergy outpatient clinic, some of them with the diagnosis based on clinical history and skin prick tests and some by oral food challenge. Community parentalreporting questionnaires, in contrast to specialized clinic studies, are important tools to assess the burden caused by food reactions on health care services, and the current study provides new data regarding this. Interestingly, the present study found a low prevalence rate of peanut allergy $(0.5 \%$ in the total population), different from what has been described in other countries such as the United States, ${ }^{17}$ France, ${ }^{16}$ and Italy. ${ }^{11}$

The reported prevalence of patients identified with presumably food-induced anaphylaxis $(0.2 \% ; 95 \% \mathrm{CI}=$ $0.09 \%-0.7 \%)$ is relatively high when compared with other studies. ${ }^{13,14,28}$ This finding was unexpected because the criteria used for defining anaphylaxis ${ }^{10}$ were definitely stringent. For children with potentially life-threatening food allergies, the school environment can present significant management challenges. A substantial proportion of FA reactions occur in school, and these reactions can be fatal. ${ }^{29}$ Over a 2 -year period, schools can expect that approximately $18 \%$ of students with food 
allergies will have at least 1 reaction in school. ${ }^{30}$ Therefore, proper prevention and preparedness to act are essential, and it is important to work with parents to identify the guidelines and resources available at the child's school.

In this study, reported FA diagnosis was associated with reported parental history of FA, personal history of atopic dermatitis, and preterm birth. Family history of atopic diseases has been described as a known risk factor for FA. ${ }^{5}$ Although it is unlikely that genetic risk factors could account for the recent increase in FA, it is nevertheless likely that there are genetic predisposing factors in their development. More recent studies suggest important gene-environment interactions in the development of food sensitization. ${ }^{21}$

The association found between FA and atopic dermatitis has already been described. ${ }^{21,22}$ A possible explanation for this association, the dual-allergen exposure hypothesis, has been previously proposed. Allergic sensitization results from cutaneous exposure, and tolerance occurs as a result of oral exposure to food. ${ }^{21}$ The association between FA, preterm birth, and low birth weight has been previously explored. ${ }^{31,32}$ A recent study proposed that the increased risk of FA among pretermborn children is predominantly because of an effect of being born preterm rather than because of low birth weight. ${ }^{31}$ This finding is also confirmed by our study, in which preterm birth was associated with an increased risk of FA. One possible explanation for this association is the finding that preterm babies have an immature intestine that allows higher gut permeability, resulting in increased absorption of antigens that are presented to the resident immune cells within the wall of the gut. ${ }^{33,34}$ In clinical practice, the identified risk factors can lead to improved prevention efforts for these populations.

The current study has limitations related to the known difficulties in doing epidemiological studies about FA. ${ }^{22}$ A parental-perceived FA questionnaire may cause misclassification error, and this could explain the high prevalence of reported FA to some foods - namely, strawberry and chocolate. Despite this, milk and egg allergy were among the top reported food allergies in this study, as previously described for children in general. ${ }^{17}$ Also, this misclassification error may be a possible explanation for the relatively high ratio of acute onset reactions. Previous studies $^{35,36}$ in different populations have shown that only about $10 \%$ of the parental-reported cases have their allergy confirmed by oral food challenge. Another important potential source of bias could arise from nonresponders, but no differences between responders and nonresponders regarding age and gender were found, and the response rate was high, comparable to those in previously published studies. ${ }^{11,18}$
On the other hand, despite these potential limitations, the main strength of this study is the large sample of evaluated children and the community-based criteria used to recruit the sample. Additionally, the strengths of our study are related to the evaluation of different characteristics of children.

In conclusion, a considerably high prevalence of parental-perceived FA in preschool-age children was observed. From a public health perspective, this crosssectional survey reinforces the burden of this disease in our society. The impact of FA on quality of life, parental and school stress, nutritional consequences of unnecessary restrictive diets, and the expenditure incurred by health care resources supports the increased need for allergy-specialized health care professionals and facilities. More accurate management of FA will increase society and individual levels of care, especially for patients with more severe forms of disease. Proper identification of risk factors for FA can lead to better prevention strategies in high-risk children.

\section{Acknowledgments}

The authors would like to express their deepest gratitude to the parents and children as well as to the caregivers for their important contribution. The authors also thank the day care center staff and the authorities involved in the study.

\section{Declaration of Conflicting Interests}

The author(s) declared no potential conflicts of interest with respect to the research, authorship, and/or publication of this article.

\section{Funding}

The author(s) disclosed receipt of the following financial support for the research, authorship, and/or publication of this article: Fundação para a Ciência e Tecnologia-ENVIRH Project PTDC/SAU-ESA/100275/2008 and PEst-OE/MAT/ UI0006/2011.

\section{References}

1. Chafen JJ, Newberry SJ, Riedl MA, et al. Diagnosing and managing common food allergies: a systematic review. JAMA. 2010;303:1848-1856.

2. Sackeyfio A, Senthinathan A, Kandaswamy P, Barry PW, Shaw B, Baker M. Diagnosis and assessment of food allergy in children and young people: summary of NICE guidance. BMJ. 2011;342:d747.

3. Fiocchi A, Schunemann HJ, Brozek J, et al. Diagnosis and Rationale for Action Against Cow's Milk Allergy (DRACMA): a summary report. J Allergy Clin Immunol. 2010;126:1119-1128.e12.

4. Urisu A, Ebisawa M, Mukoyama T, Morikawa A, Kondo N. Japanese guideline for food allergy. Allergol Int. 2011;60:221-236. 
5. Burks AW, Tang M, Sicherer S, et al. ICON: food allergy. J Allergy Clin Immunol. 2012;129:906-920.

6. Sampson HA, Munoz-Furlong A, Bock SA, et al. Symposium on the definition and management of anaphylaxis: summary report. J Allergy Clin Immunol. 2005;115:584-591.

7. Novembre E, Cianferoni A, Bernardini R, et al. Anaphylaxis in children: clinical and allergologic features. Pediatrics. 1998;101:E8.

8. Bock SA, Munoz-Furlong A, Sampson HA. Fatalities due to anaphylactic reactions to foods. J Allergy Clin Immunol. 2001;107:191-193.

9. Mehl A, Wahn U, Niggemann B. Anaphylactic reactions in children: a questionnaire-based survey in Germany. Allergy. 2005;60:1440-1445.

10. Muraro A, Roberts G, Clark A, et al. The management of anaphylaxis in childhood: position paper of the European academy of allergology and clinical immunology. Allergy. 2007;62:857-871.

11. Caffarelli C, Coscia A, Ridolo E, et al. Parents' estimate of food allergy prevalence and management in Italian school-aged children. Pediatr Int. 2011;53:505-510.

12. Decker WW, Campbell RL, Manivannan V, et al. The etiology and incidence of anaphylaxis in Rochester, Minnesota: a report from the Rochester Epidemiology Project. J Allergy Clin Immunol. 2008;122:1161-1165.

13. Braganza SC, Acworth JP, McKinnon DR, Peake JE, Brown AF. Paediatric emergency department anaphylaxis: different patterns from adults. Arch Dis Child. 2006;91:159-163.

14. Moneret-Vautrin DA, Romano MC, Kanny G, et al. The individual reception project (IRP) for anaphylactic emergencies. The situation in France and French overseas territories in 2002 [in French]. Presse Med. 2003;32:61-66.

15. Pereira B, Venter C, Grundy J, Clayton CB, Arshad SH, Dean T. Prevalence of sensitization to food allergens, reported adverse reaction to foods, food avoidance, and food hypersensitivity among teenagers. J Allergy Clin Immunol. 2005;116:884-892.

16. Rance F, Grandmottet X, Grandjean H. Prevalence and main characteristics of schoolchildren diagnosed with food allergies in France. Clin Exp Allergy. 2005;35:167-172.

17. Gupta RS, Springston EE, Warrier MR, et al. The prevalence, severity, and distribution of childhood food allergy in the United States. Pediatrics. 2011;128:e9-e17.

18. Pyrhonen K, Nayha S, Kaila M, Hiltunen L, Laara E. Occurrence of parent-reported food hypersensitivities and food allergies among children aged 1-4 yr. Pediatr Allergy Immunol. 2009;20:328-338.

19. Venter C, Pereira B, Voigt K, et al. Prevalence and cumulative incidence of food hypersensitivity in the first 3 years of life. Allergy. 2008;63:354-359.

20. Branum AM, Lukacs SL. Food allergy among children in the United States. Pediatrics. 2009;124:1549-1555.
21. Lack G. Update on risk factors for food allergy. J Allergy Clin Immunol. 2012;129:1187-1197.

22. Sicherer SH. Epidemiology of food allergy. J Allergy Clin Immunol. 2011;127:594-602.

23. Sicherer SH, Furlong TJ, Munoz-Furlong A, Burks AW, Sampson HA. A voluntary registry for peanut and tree nut allergy: characteristics of the first 5149 registrants. $J$ Allergy Clin Immunol. 2001;108:128-132.

24. Variations in the prevalence of respiratory symptoms, self-reported asthma attacks, and use of asthma medication in the European Community Respiratory Health Survey (ECRHS). Eur Respir J. 1996;9:687-695.

25. McBride D, Keil T, Grabenhenrich L, et al. The EuroPrevall birth cohort study on food allergy: baseline characteristics of 12,000 newborns and their families from nine European countries. Pediatr Allergy Immunol. 2012;23:230-239.

26. Rona RJ, Keil T, Summers C, et al. The prevalence of food allergy: a meta-analysis. J Allergy Clin Immunol. 2007;120:638-646.

27. Morais-Almeida M, Prates S, Pargana E, et al. Alergia alimentar em crianças numa consulta de imunoalergologia. Rev Port Imunoalergol. 1999;7:167-171.

28. Bohlke K, Davis RL, DeStefano F, Marcy SM, Braun MM, Thompson RS. Epidemiology of anaphylaxis among children and adolescents enrolled in a health maintenance organization. J Allergy Clin Immunol. 2004; 113:536-542.

29. Eldredge C, Schellhase K. School-based management of food allergies in children. Am Fam Physician. 2012;86: 16-18.

30. Nowak-Wegrzyn A, Conover-Walker MK, Wood RA. Food-allergic reactions in schools and preschools. Arch Pediatr Adolesc Med. 2001;155:790-795.

31. Chandran U, Demissie K, Echeverria SE, Long JB, Mizan S, Mino J. Food allergy among low birthweight children in a national survey. Matern Child Health J. 2013;17: 165-171.

32. Lucas A, Brooke OG, Cole TJ, Morley R, Bamford MF. Food and drug reactions, wheezing, and eczema in preterm infants. Arch Dis Child. 1990;65:411-415.

33. Weaver LT, Laker MF, Nelson R. Intestinal permeability in the newborn. Arch Dis Child. 1984;59:236-241.

34. Weaver LT, Laker MF, Nelson R. Enhanced intestinal permeability in preterm babies with bloody stools. Arch Dis Child. 1984;59:280-281.

35. Bock SA. Prospective appraisal of complaints of adverse reactions to foods in children during the first 3 years of life. Pediatrics. 1987;79:683-688.

36. Venter C, Pereira B, Grundy J, et al. Incidence of parentally reported and clinically diagnosed food hypersensitivity in the first year of life. J Allergy Clin Immunol. 2006;117:1118-1124. 
Copyright of Clinical Pediatrics is the property of Sage Publications Inc. and its content may not be copied or emailed to multiple sites or posted to a listserv without the copyright holder's express written permission. However, users may print, download, or email articles for individual use. 